\title{
Antegrade metal stent deployment under endoscopic ultrasound guidance using a novel uncovered metal stent with a fine-gauge stent delivery system
}

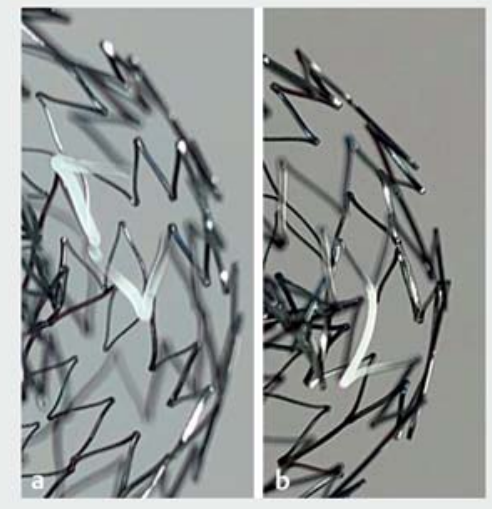

- Fig. 1 Cell width of the novel uncovered self-expandable metal stent (YABUSAME; Kaneka, Tokyo, Japan) is small compared with the conventional type, particularly in the part where bending force is applied. a YABUSAME stent. $\mathbf{b}$ Conventional uncovered self-expandable metal stent.

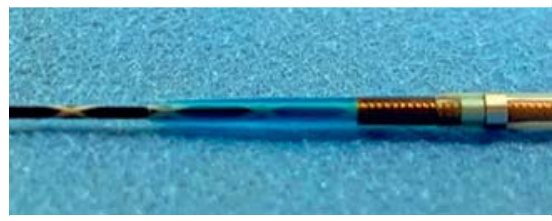

- Fig. 2 The stent delivery system is 5.4 $\mathrm{Fr}$, with an extremely tapered tip.

Endoscopic ultrasound-guided antegrade stent deployment (EUS-AS) has recently been performed for patients with inaccessible papilla, for example due to malignant duodenal obstruction or surgically altered anatomy [1-3]. During EUS-AS, use of a fine-gauge delivery system may prevent bile leakage because tract dilation may not be needed [4]. Additionally, to prevent stent misplacement or dislocation, a laser-cut-type uncovered self-expandable metal stent (UCSEMS) may be favorable compared with a fully covered metal stent (FCSEMS), although stent patency is shorter. Furthermore, cell width is high,

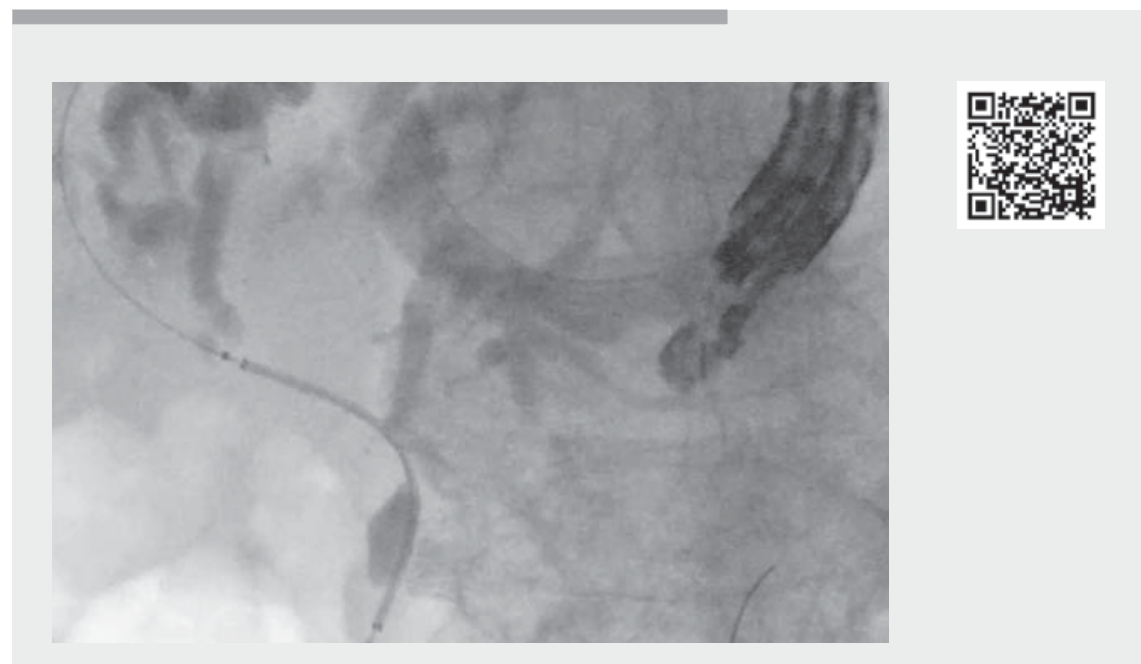

Video 1 Guidewire passage across the stricture site is successfully performed. Antegrade stent deployment using a novel uncovered self-expandable metal stent is performed without additional fistula dilation.

so stent patency may be insufficient. Recently, a novel laser-cut-type UCSEMS (YABUSAME; Kaneka, Tokyo, Japan) has become available. Cell width is smaller than in the conventional laser-cut-type UCSEMS in the part where bending force is applied ( $\triangleright$ Fig. 1). In addition, the stent delivery system is only $5.4 \mathrm{Fr}$ ( $\triangleright$ Fig. 2 ). Transluminal stent insertion can thus be performed without additional tract dilation. We describe herein technical tips for EUS-AS using this novel stent.

First, the intrahepatic bile duct is punctured using a 19-G needle, and contrast medium is injected. A 0.025 -inch guidewire is then inserted into the common bile duct. Next, an endoscopic retrograde cholangiopancreatography (ERCP) catheter is inserted into the biliary tract, and contrast medium is injected to evaluate the stricture site. After the guidewire is advanced into the intestine across the stricture site ( $\triangleright$ Fig.3), insertion of the novel stent delivery system is successfully performed without additional tract dilation ( $\triangleright$ Fig.4, $>$ Video 1 ). Stent deployment from the lower bile duct to the upper bile duct is also successfully performed (> Fig.5). Finally, metal stent deployment is performed from the intrahepatic bile duct to the stomach.

This novel UCSEMS may be useful as an antegrade stent because of the favorable stent patency and fine-gauge stent delivery system, although a prospective comparative study is needed.

Endoscopy_UCTN_Code_TTT_1AS_2AD

Competing interests

The authors declare that they have no conflict of interest.

The authors


Nobu Nishioka, Kazuhide Higuchi 2nd Department of Internal Medicine, Osaka Medical College, Osaka, Japan 


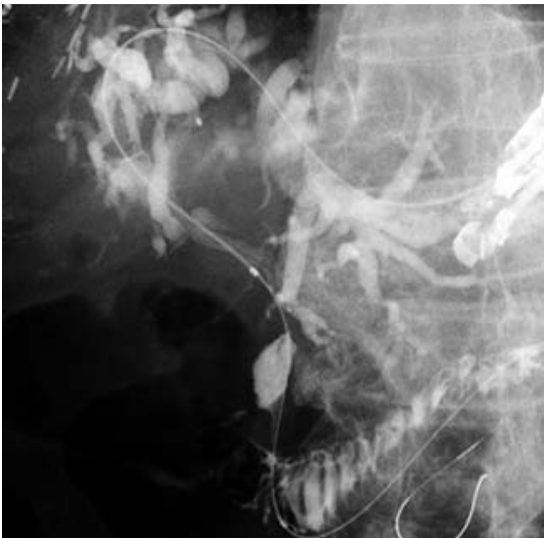

- Fig. 3 A 0.025 -inch guidewire is successfully inserted into the intestine across the stricture site.

Corresponding author

\section{Takeshi Ogura, MD}

2nd Department of Internal Medicine, Osaka Medical College, 2-7 Daigakuchou, Takatsukishi, Osaka 569-8686, Japan oguratakeshi0411@yahoo.co.jp

\section{References}

[1] Ogura T, Kitano M, Takenaka M et al. Multicenter prospective evaluation study of endoscopic ultrasound-guided hepaticogastrostomy combined with antegrade stenting (with video). Dig Endosc 2018; 30: 252-259

[2] Yamamoto K, Itoi T, Tsuchiya T et al. EUSguided antegrade metal stenting with hepaticoenterostomy using a dedicated plastic stent with a review of the literature (with video). Endosc Ultrasound 2018; 7: 404-412

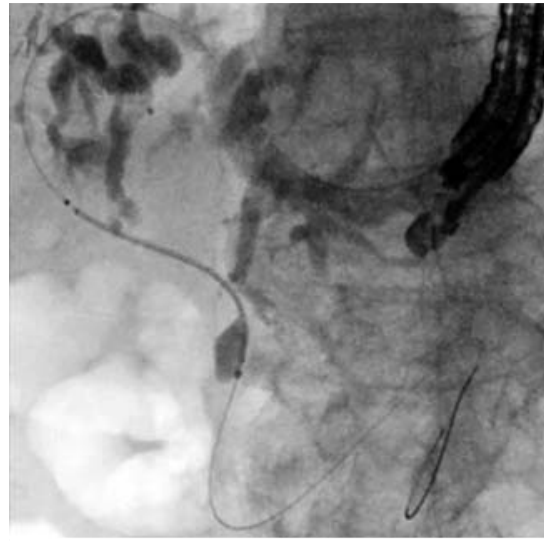

-Fig. 4 The stent delivery system is successfully inserted into the biliary tract without additional tract dilation.

[3] Iwashita T, Yasuda I, Mukai T et al. Endoscopic ultrasound-guided antegrade biliary stenting for unresectable malignant biliary obstruction in patients with surgically altered anatomy: single-center prospective pilot study. Dig Endosc 2017; 29: 362-368

[4] Ogura T, Masuda D, Imoto A et al. EUSguided hepaticogastrostomy combined with fine-gauge antegrade stenting: a pilot study. Endoscopy 2014; 46: 416-421

\section{Bibliography}

Endoscopy 2022; 54: E417-E418

DOI $10.1055 / \mathrm{a}-1562-1040$

ISSN 0013-726X

published online 8.9.2021

(c) 2021. Thieme. All rights reserved.

Georg Thieme Verlag KG, Rüdigerstraße 14,

70469 Stuttgart, Germany

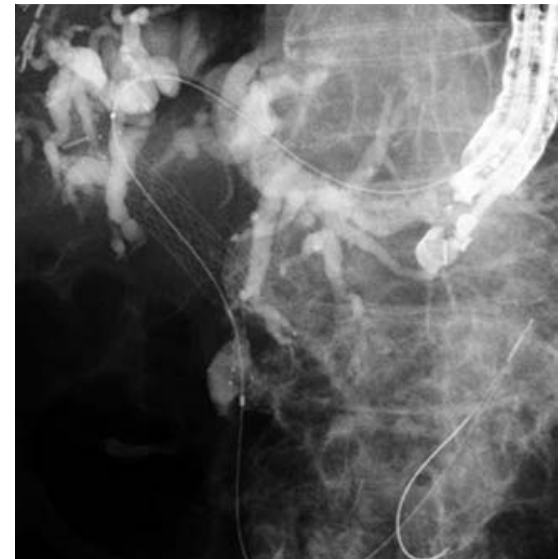

Fig. 5 Antegrade stent deployment is successfully performed.

\section{ENDOSCOPY E-VIDEOS}

https://eref.thieme.de/e-videos

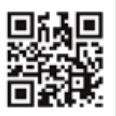

Endoscopy E-Videos is an open access online section, reporting on interesting cases and new techniques in gastroenterological endoscopy. All papers include a high quality video and all contributions are freely accessible online. Processing charges apply (currently EUR 375), discounts and wavers acc. to HINARI are available.

This section has its own submission website at https://mc.manuscriptcentral.com/e-videos 